the neuropathy was probably due to methaqualone. Methaqualone ingestion has been followed by transient paraesthesiae preceding sleep $^{4}$; however, no persistent neuropathies have been reported. He took roughly 30 tablets $-7.5 \mathrm{~g}$ of methaqualone-a severe overdose, since the minimal fatal dose of methaqualone may be under 8 g. ${ }^{5}$

Hence peripheral neuropathy should be considered as a complication-though a rare one-of Mandrax intoxication.

I am grateful to Dr. G. Danta, consultant neurologist, for his expert advice and the electromyographic studies of the patient.

1 Lawson, A. A. H., and Brown, S. S., British Medical fournal, 1966, 2, 1455. 2 Matthew, H., et al., British Medical fournal, 1968, 2, 101.

3 Matthew, p. 81. Edinburgh and London, Livingstone, 1970

4 Goodman, L. S., and Gilman, A., Pharmacological Basis of Therapeutics, p. 131. 4th edn. Baltimore, Williams and Wilkins, 1970.

5 Sanderson, T. H., Cowdell, R. H., and Higging, G., Lancet, 1966, 2, 803.

Copthorne Hospital, Shrewsbury, Shropshire

K. CONSTANTINIDIS, M.D., Membership in General Medicine (Athens), Registrar

\section{Renal Carcinoma in a Cadaver Kidney Graft Donor}

There have been two reports on the unexpected finding of a small nodule on the surface of a kidney being removed from a living donor before transplantation. In Cerelli's case reported by Penn, after biopsy of the nodule, the kidney was transplanted but removed 48 hours later because of the suspicion of malignancy. In Fox's case ${ }^{2}$ histological examination of the nodule showed a renal adenocarcinoma; the kidney was removed for therapeutic reasons and not used in the recipient. Transplantation from donors with primary malignant disease outside the central nervous system has been abandoned ${ }^{1} 3$ and apparently normal kidneys containing hidden secondary deposits have caused the recipient's death from transplanted tumour. ${ }^{4}$ This report describes the accidental transplantation of a kidney containing a primary renal carcinoma from a cadaver donor.

\section{Case History}

The donor was a 61-year-old man who had had a fatal head injury after road accident. Both kidneys were removed after cardiac arrest and the left kidney was used at the donor centre. The right kidney was taken by the organ matching service to Southmead Hospital, Bristol, for transplantatio into a 30-year-old recipient. When the kidney was revascularized a small yellowish nodule, $1 \mathrm{~cm}$ in diameter, appeared at the upper pole. The nodule was biopsied and the operation completed. The transplant functioned immediately, with a creatinine clearance of $38 \mathrm{ml} / \mathrm{min}$ by the fifth day. Microsopy of routine parafin sections of the nodule, however, showed an Ming

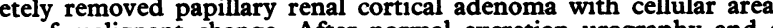
suspicious of malignant change. After normal excretion urography and

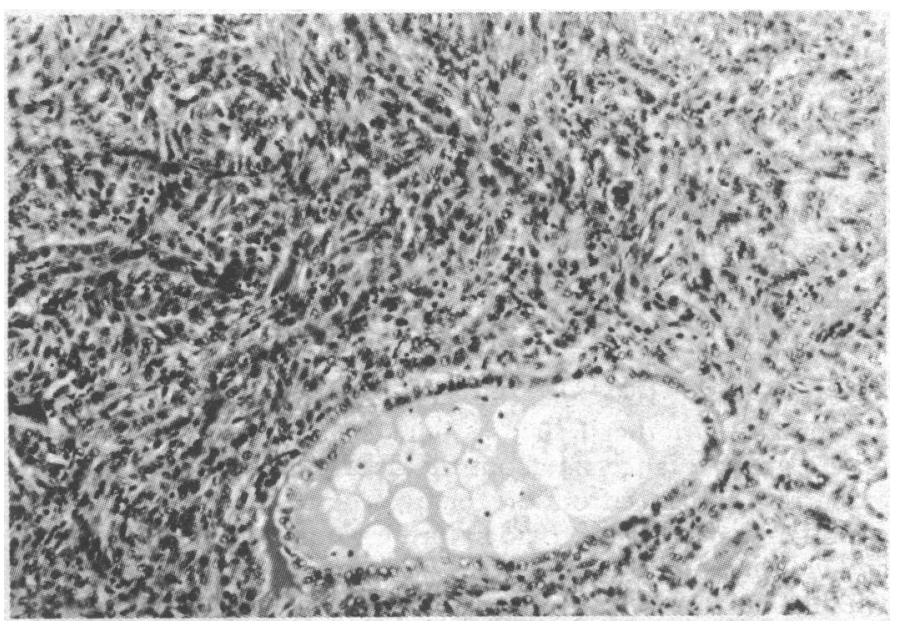

Photomicrograph from the renal cortical tumour showing a well-differentiated tubular pattern with a solid area showing loss of acinar structure and pleomorphism very suggestive of malignant change (H. \& E. $\times 139)$
On microscopy the appearances were essentially similar to the previous biopsy but there was also an area of probable early invasion (see fig.). The final pathological diagnosis was a well-differentiated primary renal cell final pathological diagnosis was a well-differentiated primary renal cell adenocarcinoma. One month after transplantation the kidney underwent was found on careful histological examination of the allograft. Meanwhile, was found on careful histological examination of the allograft. Meanwhile, necropsy had failed to show any evidence of carcinoma in the donor. The despite having had a second transplant removed because of rejection.

\section{Comment}

However carefully donors are selected, there is always the risk of transplanting a kidney containing a small malignant tumour. This case, and the recently reported similar cases, ${ }^{12}$ underline the importance of viewing any nodule on a donor kidney with the gravest suspicion. The histological differentiation between adenoma and renal cell adenocarcinoma is often difficult and proved carcinoma, have been found as small as $0.5 \mathrm{~cm}$ diameter. ${ }^{5}$ In the present case we thought that the tumour had been adequately excised, and no residual tumour was found in the rejected kidney. During cadaver nephrectomy any nodule, however apparently insignificant, should be removed at the time and subjected to immediate frozen section examination.

1 Penn, I., Transplantation, 1973, 16, 674.

2 Fox, $1 .$, Transplantation, 1973, 15, 523

3 Penn, I., Malignant Tumours in Organ Transplant Recipients, p. 7. New York, Springer-Verlag, 1970

4 Jeremy, D., et al., Transplantation, 1972, 13, 619.

Crocker, D. W., in Pathology Annual, ed. S. C. Sommers, p. 252. London, Butterworths, 1967.

\section{Southmead General Hospital, Bristol BS10 5NB}

R. N. BAIRD, M.B., F.R.C.S.(ED.), Lecturer in Surgery

H. J. O. WHITE, M.CHIR., F.R.C.S., Director, Renal Transplant Unit C. R. TRIBE, D.M., M.R.C.PATH., Consultant Pathologist

\section{Recurrent Iritis}

Catterall and Perkins ${ }^{12}$ have described cases of uveitis associated with chronic prostatitis, and bacteriological examination of the prostatic fluid showed no particular organism to be predominant. Streptococci, staphylococci, and diphtheroids were grown in most cases and Escherichia coli in a few, but, as they stated, these organisms are usually regarded as contaminants of the male urogenital tract. They found pleuropneumonia-like organisms after careful search for them in the prostatic fluid and centrifugal deposit from these in about $10 \%$ of cases with uveitis. They emphasized that acute anterior uveitis is not necessarily caused by chronic prostatitis but is strongly associated with it. Dark and Morton ${ }^{3}$ have discussed the association of acute anterior uveitis with chronic prostatitis. This is a case of iritis associated with trichomonal prostatitis.

\section{Case History} An unmarried white man, aged 29, was referred to the special clinic in Manchester Eye Hospital from the uveitis clinic with a history of recurrent attacks of iritis for six months which had failed to respond to various topical treatments. There was no history or clinical evidence of syphilis or gonorrhoea and no history of a urethral discharge. Blood Wassermann reaction and gonococcal fixation test were both negative. The patient had an acute iritis; the external genitalia were normal; no urethral discharge was detected, and his urine was normal. Microscopic examination of an unstained specimen of prostatic fluid obtained by prostatic massage showed clumps of pus cells and numerous trichomonads. A presumptive diagnosis of trichomonal seven days) was prescribed. The iritis rapidly cleared up and over a course of several months there was no recurrence.

The prompt response to metronidazole suggests that there was an association between the iritis and the trichomonal prostatitis.

1 Catterall, R. D., and Perkins, E. S., British fournal of Ophthalmology, $1961,45,109$.

3 Catterall, R. D., Lancet, 1961, 2, 739. 52, 907 .

Department of Genitourinary Medicine, Southampton University Hospitals, Southampton SO2 ONH

J. O. DOYLE, M.D., M.R.C.P., Consultant Venereologist, Clinical Teacher in Venereology 